\title{
Erratum
}

\section{Erratum to: Numerical Simulation of Groundwater Flow and Vulnerability in Wadi El-Natrun Depression and Vicinities, West Nile Delta, Egypt}

\author{
M. El Osta ${ }^{1,2 *}$, H. Hussein ${ }^{1}$, K. Tomas ${ }^{3}$ \\ ${ }^{1}$ Geology Department, Faculty of Science, Damanhour University, Egypt \\ ${ }^{2}$ Water Research Center, King Abdulaziz University, Jeddah, Saudi Arabia \\ ${ }^{3}$ Department of Geological Sciences, Faculty of Science, Masaryk University, Kotláøská 2, 61137 Brno, Czech Republic \\ *E-mail: drmagedelosta.edu.alex@hotmail.com*,hana_202040@yahoo.com; tomas@sci.muni.cz
}

In the above published article in August 2018 issue of the Journal of the Geological Society of India (v.92, pp.235-247). On page 236, Figure 1 is incorrect and should be replaced by the figure given below

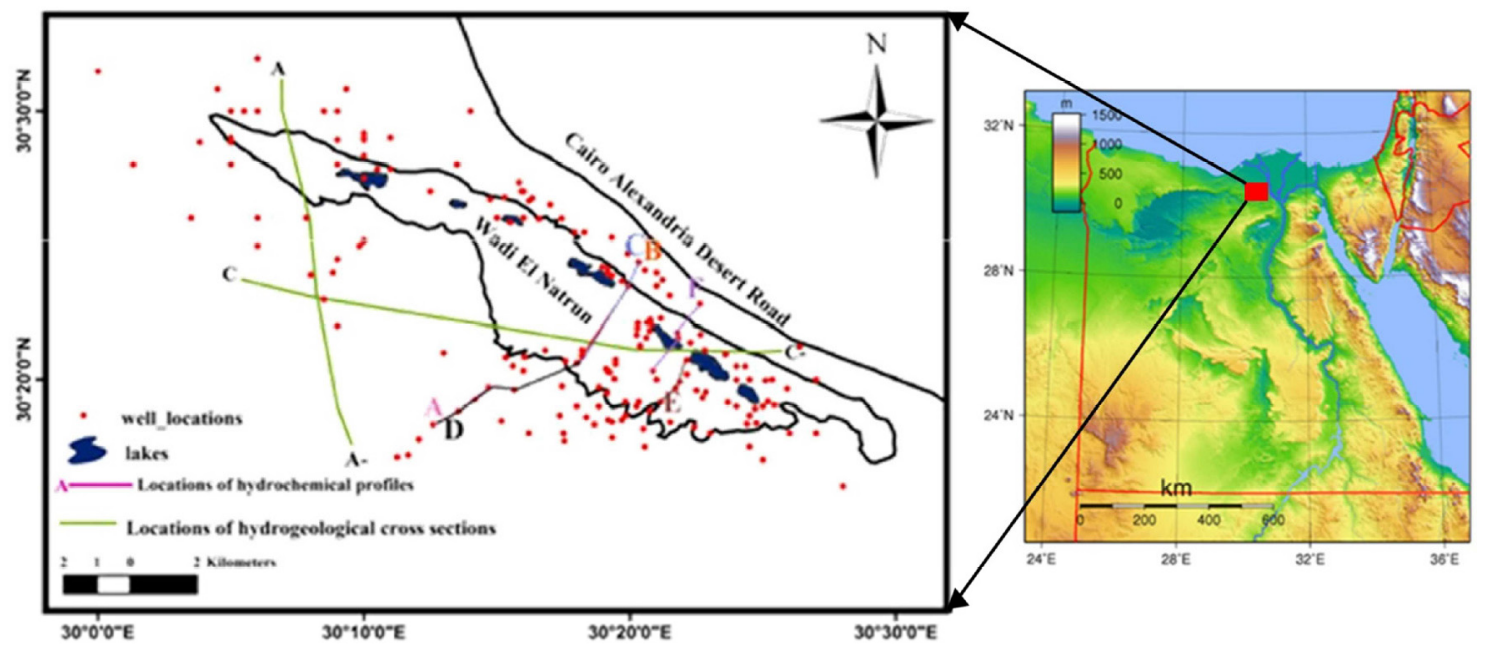

Fig.1. Location map of Wadi El - Natrun area. 